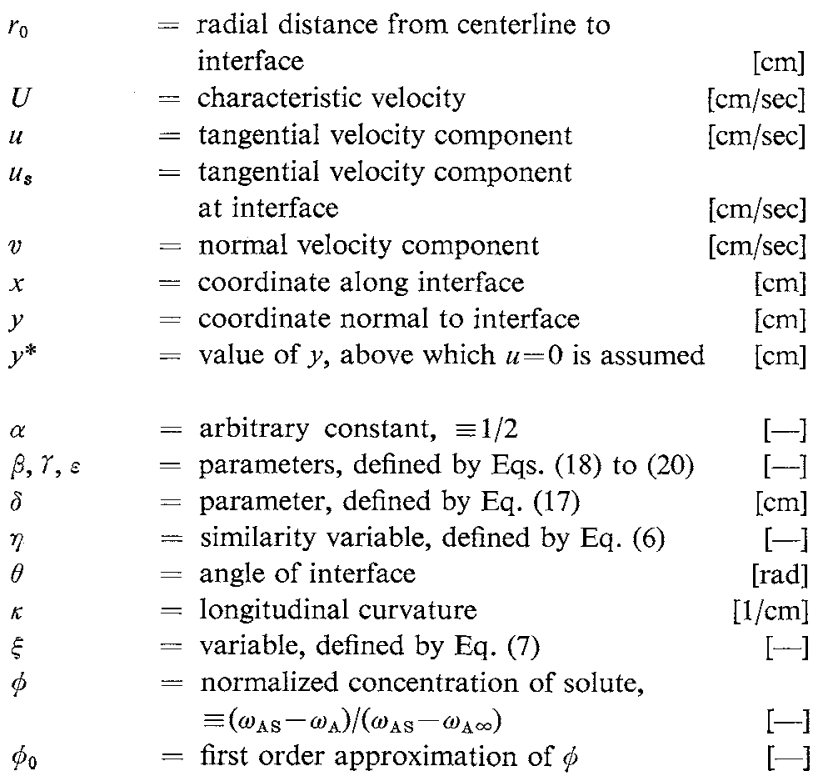

$\omega_{\mathrm{A}} \quad=$ mass fraction of solute

1) Chao, B. T.: Int. J. Heat Mass Transfer, 15, 907 (1972).

2) Chao, B. T. and R. O. Fagbenle: ibid., 17, 223 (1974).

3) Churchill, S. W. and R. Usagi: AIChE J., 18, 1121 (1972).

4) Hirose, T.: Trans. ASME., 94C, 574 (1973).

5) Lighthill, M. J.: Proc. Roy. Soc., A202, 359 (1950).

6) Merk, H. J.: J. Fluid Mech., 5, 460 (1959).

7) Nath, G.: Trans. ASME., 97I, 292 (1976).

8) Sano, T.: Int. J. Heat Mass Transfer, 18, 1257 (1975).

9) Stewart, W. E., J. B. Angelo and E. N. Lightfoot: AIChE $J ., 16,771$ (1970).

10) Ueyama, K. and J. Hatanaka: J. Chem. Eng. Japan, 5, 305 (1972).

11) Van Dyke, M.: J. Fluid Mech., 14, 161 (1962).

12) Watts, R. G.: Trans. ASME., 94C, 1 (1972).

(Presented at the 42nd Annual Meeting of The Soc. of Chem. Engrs., Japan at Hiroshima, on April 3, 1977.)

\title{
CREEP CONSTANTS IN EXPRESSION OF COMPRESSIBLE SOLID-LIQUID MIXTURES
}

\author{
Mompei SHIRATO, Toshiro MURASE, KUNIO ATSUMI, TAKATOSHI NAGAMI \\ AND Hiromi SUZUKI \\ Department of Chemical Engineering, Nagoya University, Nagoya 464
}

\section{Introduction}

Increasing interest in filter-cake dewatering ${ }^{1,3,97}$ has been shown in industry. In expression of solidliquid mixtures, dewatering proceeds rather rapidly at the beginning of expression and becomes slow with elapsed time. Especially in the later period, deliquoring proceeds at a very slow speed which is mainly dependent upon the creep effects of the solid materials in the mixture. In recent studies ${ }^{3-6}$ ) of constantpressure expression, it has been shown that the whole process of expression of solid-liquid mixtures can be accurately analysed by introducing the empirical creep constants $B$ and $\eta$ on the basis of an elaborate consolidation theory based upon the so-called Terzaghi-Voigt combined model. For a better understanding of the intrinsic nature of expression mechanisms based upon the Terzaghi-Voigt model, further experimentation on the creep constants of $B$ and $\eta$ may be needed.

The objective of this paper is the experimental in-

Received February 4,1978. Correspondence concerning this article should be addressed to M. Shirato. K. Atsumi is at Dept. of Chem. Eng., Shizuoka Univ., Hamamatsu 432. T. Nagami is now with Noritake Co., Ltd., Nagoya 467 . vestigation of the effects on the creep constants $B$ and $\eta$ of operating factors in expression operations.

\section{Experiments}

For studying the changes in the values of $B$ and $\eta$ due to applied pressure $p$ and initial average void ratio $e_{1 . \mathrm{av}}$ of expression materials, expression experiments with both filter cakes and semi-solid materials are conducted under constant-pressure conditions. Three kinds of materials, Korean kaolin, $50 \mathrm{wt} . \%$ Mitsukuri Gairome clay-50 wt. \% Standard Super-Cel mixture, and Solka Floc (BW-200), are used, their properties being tabulated in Table 1. Compression permeability cells ( 6.0 and $5.4 \mathrm{~cm}$ inside diameter) are used, and the decrease in thickness $\left(L_{1}-L\right)$ at a time $\theta_{0}$ is measured by dial gauges. The expression pressure used in this work ranges from $0.4 \mathrm{up}$ to $196 \mathrm{Kg}$-force $/ \mathrm{cm}^{2}$.

\section{Experimental Results and Discussion}

Consolidation mechanisms occur in two phenomena of void decrease $e^{2,4-8}$. In view of the fact that the decrease in a local void ratio consists of the so-called primary and secondary consolidation and that the rheological constitution can approximate to the 
Table 1 Materials used

Material

Korean kaolin

True density of solid, $\rho_{s}\left[\mathrm{~g}-\mathrm{mass} / \mathrm{cm}^{3}\right]$

Equilibrium void ratio, $e[-]$

Specific resistance, $\alpha$ [cm/g-mass]

Initial average void ratio, $e_{1 . \mathrm{av}}[-]$

Applied expression pressure, $p$ [g-force $/ \mathrm{cm}^{2}$ ]

Average value of creep constants, $B[-]$ $\eta\left[\sec ^{-1}\right]$

$$
2.59
$$

$4.52-0.369 \ln p$ $\left(600 \leq p_{s} \leq 10000\right)$

$1.24 \times 10^{12}+1.76 \times 10^{9} p_{s}^{0.922}$ $\left(600 \leq p_{s} \leq 10000\right)$

0.576 to 1.74

$1.3 \times 10^{5}$ to $1.96 \times 10^{5}$

0.030

$5.16 \times 10^{-5}$ 50wt. \% Mitsukuri Gairome clay-50wt. \% Standard SuperCel Mixture

$$
2.35
$$

$5.01-0.340 \ln p_{s}$ $\left(200 \leq p_{s} \leq 12000\right)$

$5.14 \times 10^{10}+1.65 \times 10^{8} p_{s}^{0.766}$ $\left(200 \leq p_{s} \leq 12000\right)$

1.90 to 2.54

$1.3 \times 10^{3}$ to $2.0 \times 10^{4}$

0.053

$4.76 \times 10^{-5}$
Solka Floc

(BW-200)

\author{
$9.94-0.938 \ln p_{s}$ \\ $\left(500 \leq p_{s} \leq 10000\right)$ \\ $3.74 \times 10^{8}+5.90 \times 10^{5} p_{s}^{1.02}$ \\ $\left(500 \leq p_{s} \leq 10000\right)$ \\ 0.595 to 5.54
}

$4.0 \times 10^{2}$ to $1.96 \times 10^{5}$
Terzaghi-Voigt model as formerly reported ${ }^{2,4-6)}$, the consolidation process for filter-cake expression can be represented by ${ }^{4-6)}$

$$
\begin{aligned}
U_{c} & =L_{1}-L \\
& L_{1}-L_{\infty} \\
& =(1-B)\left\{1-\exp \left(-\frac{\pi^{2} i^{2} C_{e}}{4 \omega_{0}^{2}} \theta_{c}\right)\right\}+B\left\{1-\exp \left(-\eta \theta_{c}\right)\right\}
\end{aligned}
$$

and for semi-solid material expression $b y^{4-6)}$

$$
\begin{aligned}
U_{c}=(1-B)\left[1-\sum_{N=1}^{\infty} \frac{8}{\pi^{2}(2 N-1)^{2}}\right. \\
\left.\quad \exp \left\{-\frac{(2 N-1)^{2} i^{2} \pi^{2} C_{e}}{4 \omega_{0}^{2}}-\theta_{c}\right\}\right]+B\left[1-\exp \left(-\eta \theta_{c}\right)\right]
\end{aligned}
$$

where $U_{c}$ is the average consolidation ratio at a consolidation time $\theta_{c}, L_{1}$ the initial thickness when $\theta_{c}=0, L$ the thickness at a time $\theta_{c}, L_{\infty}$ the final thickness when $\theta_{c}=\infty, C_{e}$ the modified consolidation coefficient, $i$ the number of drainage surfaces, $\omega_{0}$ the total solid volume per unit sectional area, $\eta$ the empirical constant with respect to the deliquoring rate due to creep effects, and $B$ is the empirical constant defined by

$$
B=\left(L_{1}-L_{\infty}\right)_{c} /\left(L_{1}-L_{\infty}\right)
$$

In Eq. (3), $\left(L_{1}-L_{\infty}\right)_{c}$ indicates the maximum liquid volume deliquored by secondary consolidation.

Generally, the time rates of secondary consolidation are much smaller than those of primary consolidation. In view of the fact ${ }^{4-6)}$ that $\eta \ll C_{\theta}\left(i \pi / 2 \omega_{0}\right)^{2}$, Eqs. (1) and (2) become approximately Eq. (4) when $\theta_{c} \gg 0$

$$
U_{c} \fallingdotseq 1-B \cdot \exp \left(-\eta \theta_{c}\right)
$$

and the values of $B$ and $\eta$ can be graphically determined from experimental data in the later stages of $\ln \left(1-U_{c}\right)$ vs. $\theta_{c}$ as illustrated in Fig. 1. As may be seen from Fig. 1, the experimental values of $B$ depend upon both the applied pressure $p$ and the initial average void ratio $e_{1 . \mathrm{av}}$, whereas the values of $\eta$ are substantially constant. The experimental $B$ values are shown for various $p / p_{s}\left(e_{1 . \mathrm{qv}}\right)$ values in Fig. 2, where $p_{*}\left(e_{\text {1. av }}\right)$ denotes

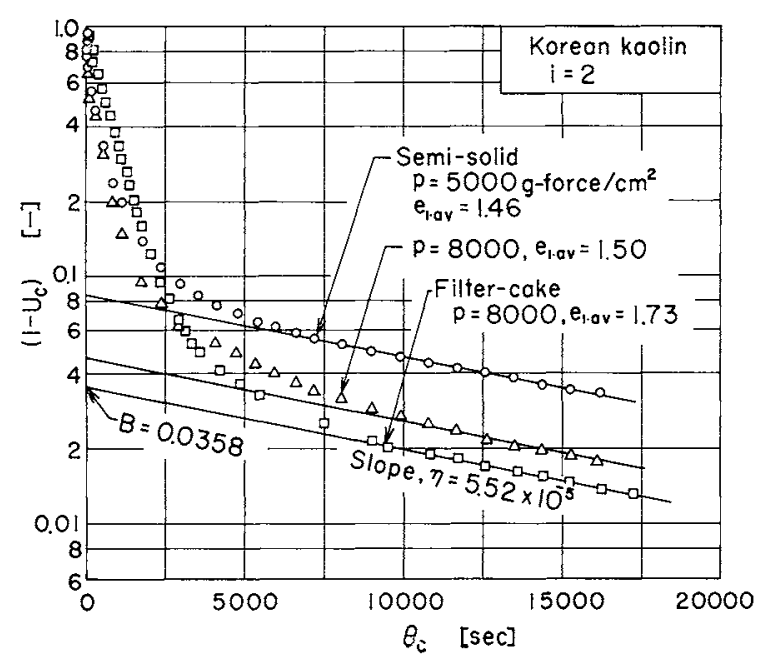

Fig. $1 \ln \left(1-U_{c}\right)$ vs. $\theta_{c}$

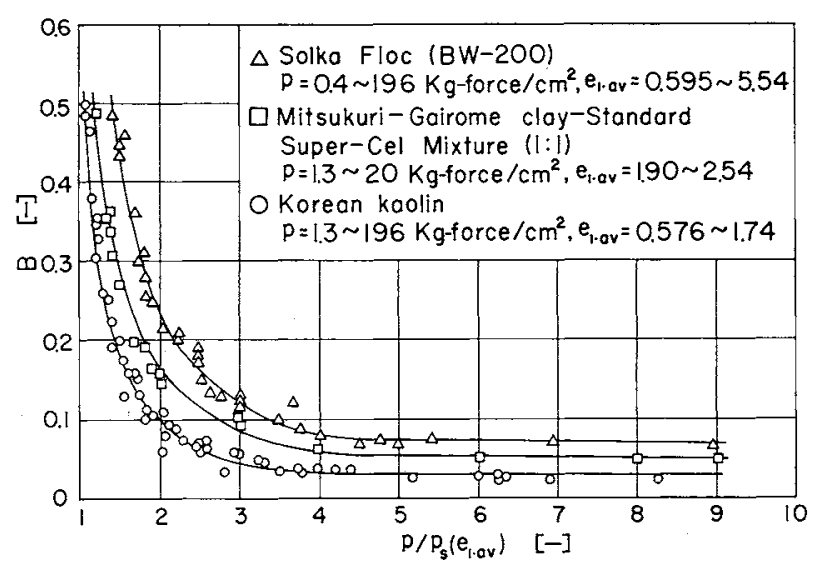

Fig. $2 B$ vs. $p / p_{s}\left(e_{1 \cdot a v}\right)$

the solid compressive pressure which yields the equilibrium void ratio of compressed cake $e_{1 . a v}$ in compression-permeability cell measurements. It can be seen from the figure that $B$ is substantially constant for $p / p_{\mathrm{s}}\left(e_{1 . \mathrm{av}}\right)$ larger than a limiting value. In Fig. 3, $p / p_{s}\left(e_{1 . \mathrm{aV}}\right)$ vs. $p$ for filter cake expression of three materials are shown when expressions are conducted 


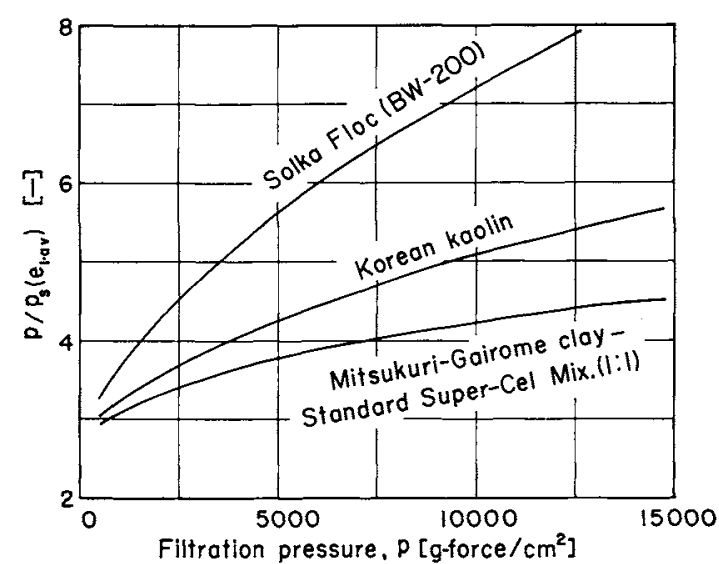

Fig. 3 Theoretical $p / p_{s}\left(e_{1} \cdot{ }_{\mathrm{q}}\right)$ values of filter cakes

under the same pressure as the filtration pressure. The $p / p_{s}\left(e_{1 . a v}\right)$ values for filter-cake expression in industrial practice are larger than about 3 or 4 , as may be seen from Fig. 3. Therefore, it can be safely concluded that the values of both $B$ and $\eta$ are approximately constant for practical expression operations, and they can be viewed as the expression characteristics of the materials themselves. The experimental values of $B$ and $\eta$ are also tabulated in Table 1 .

\section{Acknowledgment}

This work was supported by the Science Research Foundation of the Education Ministry, Japan, Grant No. 210413, and by Takeda Science Foundation, Osaka, Japan. The authors wish to acknowledge their support leading to the publication of this article.

Nomenclature

$B \quad=$ creep constant defined by Eq. (3)

$C_{e} \quad=$ consolidation coefficient $\left[\mathrm{cm}^{2} / \mathrm{sec}\right]$

$e_{\text {av }}=$ initial average void ratio of mixture at the beginning of consolidation

$\begin{array}{ll}e_{\infty} & =\text { final equilibrium void ratio } \\ i & =\text { number of drainage surfaces }\end{array}$

$[-]$

$L \quad=$ thickness of compressed cake at a time $\theta_{c} \quad$ [cm]

$L_{1} \quad=$ initial thickness of original cake when $\theta_{c}=0$

$[\mathrm{cm}]$

$L_{\infty} \quad=$ final thickness of compressed cake when $\theta_{c}=\infty$

[cm]

$p \quad=$ applied expression pressure $\quad\left[\mathrm{g}-\mathrm{force} / \mathrm{cm}^{2}\right]$

$p_{s} \quad=$ local solid compressive pressure $\quad\left[\mathrm{g}-\right.$ force $/ \mathrm{cm}^{2}$ ]

$p_{s}\left(e_{1, \mathrm{av}}\right)=$ solid compressive pressure where the equilibrium void ratio of compressed cake $e_{1 . a, \mathrm{~V}}$ is attained [g-force $/ \mathrm{cm}^{2}$ ]

$U_{c} \quad=$ average consolidation ratio $\quad[-]$

$\alpha \quad=$ local specific resistance of cake $\quad[\mathrm{cm} / \mathrm{g}$-mass]

$\eta \quad=$ creep constant [ $\left.\mathrm{sec}^{-1}\right]$

$\theta_{c} \quad=$ consolidation time [sec]

$\rho_{s} \quad=$ true density of solid $\quad\left[\mathrm{g}-\mathrm{mass} / \mathrm{cm}^{3}\right]$

$\omega_{0} \quad=$ total solid volume in original mixture per unit sectional area

[cm]

\section{Literature Cited}

1) Dahlstrom, D. A.: The Second Pacific Chem. Eng. Congress, 1, 957 (1977).

2) Ishii, Y., S. Kurata and S. Fukaya: Dobokugakkai Ronbunshu, No. 30, 1 (1955).

3) Shirato, M., T. Murase and T. Aragaki: "Neue Prinzipien der Mechanischen Verfahrentechnik", Dechema Monographien, Nr. 1432-1451, Br. 74 (1974).

4) Shirato, M., T. Murase and O. Yamada: J. Chem. Eng. Japan, 7, 299 (1974).

5) Shirato, M., T. Murase, N. Hayashi and T. Fukushima: ibid., 10, 154 (1977).

6) Shirato, M., T. Murase and N. Hayashi: The Second Pacific Chem. Eng. Congress, 1, 677 (1977).

7) Taylor, D. W. and M. Merchant: J. Math. \& Phys., 19, 167 (1940).

8) Terzaghi, K. and R. B. Peck: "Soil Mechanics in Engineering Practice", 51, John Wiley \& Sons, Inc. (1948).

9) Tiller, F. M. and K. S. Cheng: Filtration and Separation, 14, 13 (1977). 